\title{
El derecho de residencia en la Unión Europea de matrimonios entre personas del mismo sexo
}

\author{
Right of Residence in the European Union of Same-Sex Marriages
}

\author{
María Dolores Ortiz Vidal \\ Universidad de Murcia \\ md.ortizvidal@um.es
}

Sumario: I. Introducción.-II. El derecho de los ciudadanos de la Unión Europea a la libre circulación y residencia en el territorio de los Estados miembros y a la no discriminación por razón de su nacionalidad.-III. El concepto de «cónyuge» en el marco de la Directiva 2004/38, relativa al derecho de los ciudadanos de la Unión y de los miembros de su familia a circular y residir libremente en el territorio de los Estados miembros.-IV. Matrimonio entre personas del mismo sexo y Derecho internacional privado de la Unión Europea. 1. La regla de reconocimiento y su ámbito jurídico de actuación: dimensión patrimonial vs. dimensión humana. 2. El reconocimiento de los matrimonios celebrados entre personas del mismo sexo y el derecho a circular y residir libremente en el territorio de los Estados miembros de la Unión Europea.-V. Conclusiones.

Resumen: El estado civil de las personas físicas es competencia de cada Estado miembro. Por tanto, cada Estado miembro de la Unión Europea decide - con arreglo a su identidad nacional - si es válida, o no, la celebración en su país de un matrimonio entre personas del mismo sexo. Ahora bien, el no reconocimiento de esta situación limita el derecho de los ciudadanos de la Unión Europea y de los miembros de su familia a circular y residir libremente en el territorio de los Estados miembros. Ante esta situación, el presente trabajo valora si, una discriminación basada en la orientación sexual puede obligar a los Estados miembros de la Unión Europea a reconsiderar la institución jurídica del matrimonio, respecto del ejercicio del derecho a la libre circulación y residencia. La respuesta posibilitará, o no, que el nacional de un tercer Estado que contrae válido matrimonio homosexual con otro ciudadano de la Unión Europea pueda acompañarlo, en el caso de que, por cualquier motivo que cubra sus intereses, ambos decidan trasladar su residencia de un Estado miembro a otro.

Palabras clave: Matrimonio entre personas del mismo sexo, libre circulación de personas en la Unión Europea, cónyuge, principio de mutuo reconocimiento , orden público internacional. 
Abstract: The marital status of natural persons fall under the remit of each Member State. Therefore, each Member State of the European Union decides according to its national identity - whether or not the celebration in its country of a marriage between people of the same sex is valid. However, failure to recognize this situation limits the right of citizens of the European Union and their family members to move and reside freely within the territory of the Member States. In view of this situation, the present paper assesses whether discrimination based on sexual orientation can force the Member States of the European Union to reconsider the legal institution of marriage, with respect to the exercise of the right to free movement and residence. The answer will enable, or not, the third State national who contracts a valid homosexual marriage with another citizen of the European Union to accompany the spouse, in case, for any reason that covers their interests, both decide to move their residence from a Member State to another.

Keywords: Same-sex marriage, free movement of persons in the EU, spouse, principle of mutual recognition, international public order.

\section{Introducción}

Durante muchos años, la institución jurídica del matrimonio ha sido considerada el origen del núcleo familiar. Sin embargo, en la actualidad, el matrimonio no es el único modelo de familia. En la sociedad actual, en realidad, no existe un solo modelo de familia, sino que, concurren varios. Sirvan como ejemplos, entre otros, la familia monoparental, ensamblada u homoparental ${ }^{1}$. En consecuencia, la familia es una realidad social que no se presenta como una categoría inmutable, sino que, es una institución jurídica que varía en función del espacio y del tiempo en el que ésta se ubique ${ }^{2}$.

En este contexto, hoy en día, la movilidad transfronteriza de las personas se produce cada vez con más frecuencia, en virtud del derecho fundamental que se le reconoce a los ciudadanos de la Unión Europea y a los miembros de su familia - independientemente de su nacionalidad - a circular y residir libremente en el territorio de los Estados miembros ${ }^{3}$. Ello

${ }^{1}$ Ricardo Montoro Romero y Javier Elzo Imaz, «La familia en la sociedad del siglo XXI», Revista Javeriana, n. ${ }^{\circ} 737$ (2007): 56-63.

2 Elena Tordesillas Escudero, «El matrimonio entre personas del mismo sexo en Derecho internacional privado, Derechos civiles y Derechos Humanos afectados en diferentes países», Universitas, n. $^{\circ} 24$ (2016): 76-133.

${ }^{3}$ Directiva 2004/38, de 29 de abril de 2004, relativa al derecho de los ciudadanos de la Unión y de los miembros de sus familias a circular y residir libremente en el territorio de los Estados miembros por la que se modifica el Reglamento (CEE) N. $.^{\circ} 1612 / 68$ y se derogan las Directivas 64/221/CEE, 68/360/CEE, 72/194/CEE, 73/148/CEE, 75/34/CEE, 75/35/CEE, 90/364/CEE, 90/365/CEE y 93/96/CEE (DOUE L 158/77, de 30 de abril de 2004). 
implica, entre otras muchas cosas, un aumento significativo de las uniones entre nacionales de Estados miembros distintos y/o un número elevado de estas parejas en un Estado del que no son nacionales ${ }^{4}$.

En particular, el presente trabajo se centra en el estudio de los matrimonios celebrados entre personas del mismo sexo, que no constituye, en absoluto, un fenómeno aislado. Prueba de ello, es que el Instituto Nacional de Estadística, señala que se contrajeron en 2017, sólo en España, un total de 4.606 matrimonios homosexuales ${ }^{5}$. Ahora bien, el estado civil es competencia de cada Estado miembro. Ello implica la existencia de sistemas jurídicos divergentes en la Unión Europea: ni todos los Estados miembros admiten la válida celebración en su territorio de matrimonios entre personas del mismo sexo, ni todos los Estados miembros reconocen los efectos jurídicos que derivan de la válida celebración de éstos en otros países de la Unión Europea, tal y como se verá más adelante.

Esta situación incide directamente en el derecho fundamental que la Unión Europea reconoce a sus ciudadanos y a los miembros de su familia - independientemente de su nacionalidad - a circular y residir libremente en el territorio de los Estados miembros. Por este motivo, el presente trabajo se plantea si los Estados miembros deben reconocer los matrimonios entre personas del mismo sexo válidamente celebrados en la Unión Europea o si rechazar su reconocimiento implica un aceptado límite del derecho a la libre circulación y residencia de los ciudadanos de la Unión Europea y de los miembros de su familia.

Para ello, el primer paso es dotar de significado el concepto de «cónyuge» en el marco de la libre circulación y residencia de los ciudadanos de la Unión Europea y de los miembros de su familia en el territorio de los Estados miembros. Sin embargo, ello no es una tarea fácil. De un lado, todos los Estados miembros de la Unión Europea coinciden en que la intimidad personal y familiar, la libertad del individuo e incluso su propia dignidad son criterios que forman parte del derecho a contraer matrimonio. De otro lado, la opción sexual elegida no figura en la definición de matrimonio proporcionada por algunos Estados miembros de la Unión Europea ${ }^{6}$. Ante esta

${ }^{4}$ María Pilar Diago Diago, «El matrimonio y su crisis ante los nuevos retos de la autonomía de la voluntad conflictual», Revista Española de Derecho Internacional, n. ${ }^{\circ} 2$ (2014): 49-79.

5 http://www .europapress.es/epsocial/igualdad/noticia-trece-anos-matrimonio-igualitario-espana-20180630123554.html

6 Ana Quiñones Escámez, «Derecho comunitario, derechos fundamentales y denegación del cambio de sexo y apellidos: ¿un orden público europeo armonizador? (a propósito de la SSTJCE, asuntos K.B. y García Avello)», RDCE, n. ${ }^{\circ} 18$ (2004): 507-529, esp. 522. La autora afirma que «no parece posible referirse a un derecho matrimonial europeo, pero sí garantizar la eficacia del principio de no discriminación por razón de sexo». 
situación, el presente trabajo hará también referencia a la Sentencia del Tribunal de Justicia de la Unión Europea de 5 de junio de 2018 para arrojar luz sobre ello ${ }^{7}$.

\section{EI derecho de los ciudadanos de la Unión Europea a la libre circulación y residencia en el territorio de los Estados miembros y a la no discriminación por razón de su nacionalidad}

Todo ciudadano de la Unión Europea tiene derecho a residir y a circular libremente por el territorio de los Estados miembros, con sujeción a las limitaciones y condiciones previstas en los Tratados y en las disposiciones adoptadas para su aplicación, tal y como establece el artículo 21.1 TFUE.

De ello puede desprenderse que se crea una ciudadanía de la Unión Europea, en la que se consideran ciudadanos de la Unión todos aquellos que ostenten la nacionalidad de un Estado miembro (art. 20 TFUE y 9 TUE). El estatuto de ciudadanía de la Unión Europea arranca de la idea de que un Estado no puede negar a sus propios nacionales el derecho a residir en su territorio. Ahora bien, el concepto de «estatuto de ciudadanía» ha evolucionado y permite, en este momento, que un ciudadano de la Unión Europea pueda circular libremente por otros Estados miembros de los que no es nacional ${ }^{8}$.

No obstante lo anterior, esta nueva categoría ni elimina ni sustituye a la institución clásica de la nacionalidad o ciudadanía estatal. La ciudadanía de la Unión Europea presupone la ciudadanía de un Estado miembro y coexiste indisolublemente con aquélla ${ }^{9}$. En consecuencia, se establece un vínculo indisociable entre la nacionalidad de un Estado miembro y la ciuda-

7 STJUE de 5 de junio de 2018, Coman y Hamilton, as. C-673/16, cuyos hechos pueden concretarse en los siguientes: el Sr. Coman, nacional rumano y estadounidense, y el Sr. Hamilton, nacional estadounidense, se conocieron en Nueva York en junio de 2002. En 2010, los dos contrajeron matrimonio en Bruselas porque el Sr. Coman residía allí, trabajando como asistente en el Parlamento Europeo.

En 2012, los Sres. Coman y Hamilton acudieron a la Inspección, con el objetivo de que les indicaran el procedimiento a seguir para que el Sr. Hamilton, en calidad de cónyuge del Sr. Coman, pudiera obtener el derecho a residir legalmente en Rumanía por un período superior a tres meses. La Inspección les informó de que ello no era posible porque el Código Civil rumano no reconoce como válida la celebración del matrimonio entre personas del mismo sexo. Por tanto, el Sr. Hamilton únicamente podía disfrutar de un período de residencia no superior a tres meses.

${ }^{8}$ Diana Marín Consanau, «Nuevos matices a la protección que ofrece el estatuto de ciudadanía de la Unión», Revista de Derecho Comunitario Europeo, n. ${ }^{\circ} 41$ (2012): 221-236, esp. 226.

9 Araceli Mangas Martín y Diego J. Liñán Nogueras, Instituciones y Derecho de la Unión Europea (Madrid: Tecnos, 2016), 152-153. 
danía de la Unión Europea ${ }^{10}$. Por tanto, si se pierde la condición de nacional de un Estado miembro, automáticamente, también se pierde la ciudadanía de la Unión Europea ${ }^{11}$.

En este contexto, el derecho de libre circulación y de residencia presenta una vocación expansiva ${ }^{12}$ : los ciudadanos que pueden disfrutar de este derecho son tanto los que lo ejercen por motivos económicos, como aquellos que lo hacen por razones ajenas a ello. Esta situación permite incluir a colectivos de cualquier índole. Valgan como ejemplos, entre otros, estudiantes, personas que buscan un empleo, jubilados, turistas o ciudadanos que se ven expuestos, de manera involuntaria, a situaciones transfronterizas.

En este sentido, el destinatario del derecho de libre circulación y residencia es, en la mayoría de los casos, el Estado miembro de acogida del ciudadano de la Unión, que puede concretarse en el Estado miembro del que no es nacional el ciudadano y donde éste decide trasladarse o establecer su residencia. Ahora bien, el Tribunal de Justicia de la Unión Europea ha señalado que de este derecho de libre circulación y residencia también pueden beneficiarse aquellos ciudadanos de la Unión Europea que ejercen la libre circulación y, al regresar al Estado miembro del que son nacionales, sufren algún tipo de restricción ${ }^{13}$. Ello encuentra justificación en que, el ciudadano de la Unión tiene la expectativa legítima de que se mantenga la continuidad de la relación familiar constituida en otro Estado miembro de la Unión cuando retorna a su Estado de origen ${ }^{14}$.

A ello hay que añadir que, para que el derecho de todo ciudadano de la Unión Europea a circular y residir libremente en el territorio de los Estados miembros pueda ejercerse en condiciones objetivas de libertad y dignidad, debe serle reconocido también a los miembros de su familia, cualquiera que sea su nacionalidad. En consecuencia, no sólo los ciudadanos de la Unión Europea se benefician del derecho a la libre circulación y residencia en el

10 STJUE de 2 de junio de 2016, Bogendorff von Wolffersdorff, as. C-438/14, FD. 29. El Tribunal de Justicia de la Unión Europea da un paso más, señalando en este caso que la vocación del estatuto de ciudadanía de la Unión es convertirse en el estatuto fundamental de los nacionales de los Estados miembros.

11 STJUE de 2 de marzo de 2010, Rottmann y Freistaat Bayern, as. C-135/08. En este caso, el Tribunal de Justicia de la Unión Europea señala que se debe tomar en consideración el principio de proporcionalidad si el efecto que deriva de la pérdida de la ciudadanía de la Unión es la apatridia.

12 Daniel Sarmiento Ramírez-Escudero, Derecho de la Unión Europea (Madrid: Marcial Pons, 2016), 166.

13 STJUE de 12 de julio de 2005, Schempp, as. C-403/03.

14 Pilar Jiménez Blanco, «Doble nacionalidad y derecho de residencia de los miembros de la familia del ciudadano de la Unión. Sentencia del Tribunal de Justicia de 14 de noviembre de 2017, asunto C-165/16: Lounes», La Ley Unión Europea, n. ${ }^{\circ} 56$ (2018): versión on line. 
territorio de los Estados miembros, sino también, de manera indirecta, los familiares que dependan de ellos, independientemente de que ostenten la nacionalidad de un Estado miembro o la nacionalidad de un tercer Estado ${ }^{15}$.

En otro orden de cosas, pero relacionado con lo anterior, el principal acto de desarrollo del artículo 21.1 TFUE es la Directiva 2004/38, relativa al derecho de los ciudadanos de la Unión y de los miembros de sus familias a circular y residir libremente en el territorio de los Estados miembros.

La Directiva 2004/38 establece que los ciudadanos de la Unión Europea pueden disfrutar del derecho de residencia en el Estado miembro de acogida, durante un período que no supere los tres meses, sin estar supeditados a más condiciones o formalidades que la posesión de un documento de identidad o un pasaporte válido (Cons. 9 y art. 6.1 Dir. 2004/38). De esta misma situación podrán beneficiarse los miembros de la familia en posesión de un pasaporte válido que no sean nacionales de un Estado miembro y acompañen al ciudadano de la Unión, o se reúnan con él (art. 6.2 Dir. 2004/38).

Ahora bien, en el caso de períodos de residencia superiores a tres meses, los Estados miembros deben poder requerir el registro del ciudadano de la Unión ante las autoridades competentes del lugar de residencia (Cons. 12 Dir. 2004/38). En concreto, señala la Directiva 2004/38, que todo ciudadano de la Unión tiene derecho de residencia en el territorio de otro Estado miembro, por un período superior a tres meses, si es un trabajador por cuenta ajena o por cuenta propia en el Estado miembro de acogida o si es un estudiante matriculado en un centro público o privado, reconocido o financiado por el Estado miembro de acogida con arreglo a su legislación o a su práctica administrativa, con la finalidad principal de cursar estudios, incluidos los de formación profesional.

En ambos casos, el trabajador y el estudiante deben contar con un seguro de enfermedad que cubra todos los riesgos en el Estado miembro de acogida y tienen que garantizar a la autoridad nacional competente, mediante una declaración o por cualquier otro medio equivalente de su elección, que poseen recursos económicos suficientes para no convertirse en una carga para la asistencia social del Estado miembro de acogida durante su período de residencia (art. 7.1 Dir. 2004/38).

Esta misma situación se ampliará a los miembros de la familia que no sean nacionales de un Estado miembro cuando acompañen al ciudadano de la Unión Europea o se reúnan con él en el Estado miembro de acogida (art. 7.2 Dir. 2004/38). En estos supuestos, los ciudadanos y sus familias pueden estar obligados a registrarse ante las autoridades del Estado miem-

15 STJCE 19 de octubre de 2004, Zhu y Chen, as. C-200/02. 
bro de acogida y, en su caso, a solicitar la emisión de una tarjeta de residencia. Ahora bien, el título de residencia es meramente declarativo. Por tanto, el hecho de que el ciudadano de la Unión Europea no haya solicitado una tarjeta de residencia, no comporta, necesariamente, que se le puede privar del derecho a la libre circulación ${ }^{16}$.

Ello no es baladí porque si el Derecho de la Unión Europea resulta aplicable, el familiar - nacional de un tercer Estado - se beneficiará, en el territorio del que es nacional el ciudadano de la Unión, del régimen de extranjería previsto en el Derecho de la Unión Europea. A diferencia de ello, si el Derecho de la Unión Europea no es aplicable, el familiar - nacional de un tercer Estado - quedará sujeto al régimen general de extranjería de dicho Estado que, con frecuencia, suele ser más estricto que el establecido en la Unión Europea ${ }^{17}$.

En relación con lo anterior, aunque el derecho de no discriminación por razón de la nacionalidad no se enuncia formalmente entre los derechos de ciudadanía (vid. art. 20 TFUE), destaca en calidad de principio del sistema jurídico-político de la integración, aportando unas posibilidades inmensas a todos los restantes derechos y, en especial, al derecho a la libre circulación y residencia del que es titular todo ciudadano de la Unión Europea (art. 18 TFUE $)^{18}$.

Ambos derechos - de libre circulación y residencia y a no ser discriminado por razón de la nacionalidad - han demostrado poseer unas virtualidades integradoras impensables: su vis expansiva, reconocida por el Tribunal de Justicia de la Unión Europea ha sido tal que prácticamente ha permitido el ejercicio de derechos comunes, independientemente del vínculo de la nacionalidad ${ }^{19}$.

En consecuencia, la vocación del estatuto de ciudadano de la Unión Europea es convertirse en el estatuto fundamental de los nacionales de los Estados miembros y permitir a aquellos de dichos ciudadanos que se encuentran en la misma situación obtener, independientemente de su nacionalidad y sin perjuicio de las excepciones expresamente previstas a este respecto, el mismo trato jurídico ${ }^{20}$.

16 STJCE de 8 de abril de 1976, Royer, as. 48/75, FD. 23.

17 Mónica Vinaixa Miquel, «El derecho de residencia de los nacionales de terceros Estados, familiares de ciudadano de la UE, en el territorio de origen. Comentario a la STJUE de 12 de marzo de 2014, as. C-456/2012, O y Minister voor Immigratie, Integratie en Asiel y Minister voor Immigratie, Integratie en Asiel y B», La Ley Unión Europea, n. ${ }^{\circ} 16$ (2014): versión on line.

18 STJUE de 25 de enero de 2011, Neukirchinger, as. C-382/08.

19 Araceli Mangas Martín y Diego J. Liñán Nogueras, Instituciones y Derecho de la Unión Europea (Madrid: Tecnos, 2016), 154.

${ }^{20}$ STJCE de 20 de septiembre de 2001, Rudy Grzelzczik, as. C-184/99, FD. 31. 
Ahora bien, el derecho de libre circulación y residencia de la ciudadanía de la Unión en los territorios de los Estados miembros no presenta un carácter ilimitado: su ejercicio puede someterse a condiciones, que serán susceptibles de control por parte del Tribunal de Justicia de la Unión Europea y objeto de una interpretación restrictiva ${ }^{21}$. En concreto, los Estados miembros podrán limitar la libertad de circulación y residencia de un ciudadano de la Unión o de un miembro de su familia - independientemente de la nacionalidad que ostente - por razones de orden público, seguridad pública o salud pública, siempre que estos motivos no se aleguen con fines económicos (art. 27.1 Dir. 2004/38).

La pregunta surge espontáneamente: ¿qué debe entenderse por razones de orden público, seguridad y salud pública? La Directiva 2004/38 señala que las medidas adoptadas por razones de orden público o de seguridad pública deben fundamentarse, en exclusiva, en la conducta personal del interesado. A ello hay que añadir que ésta debe constituir una amenaza real, actual y suficientemente grave que afecte al interés fundamental de la sociedad (art. 27.2 Dir. 2004/38) 22 $^{2}$ En este sentido, el Tribunal de Justicia de la Unión Europea ha señalado que no cabe admitir la excepción de orden público con carácter preventivo ${ }^{23}$, ni como medio de disuasión respecto de otros ciudadanos extranjeros ${ }^{24}$.

Por tanto, la mera existencia de condenas penales no constituye, por sí sola, un motivo suficiente para activar la cláusula de orden público o de seguridad pública ${ }^{25}$. La existencia de una condena penal sólo puede justificar una expulsión en la medida en que las circunstancias que dieron lugar a dicha condena pongan de manifiesto la existencia de un comportamiento personal que constituye una amenaza actual para el orden público del Estado miembro de acogida ${ }^{26}$.

Además, las restricciones al derecho de libre circulación y residencia del ciudadano de la Unión y de los miembros de su familia no deben exceder de lo que es considerado legítimo en virtud del principio de proporcionalidad y de las condiciones y límites establecidos en los Tratados de la Unión Europea. En esta línea de pensamiento, el Tribunal de Justicia de la Unión Europea ha advertido que es el Derecho de la Unión Europea el que

${ }^{21}$ Jacqueline Hellman y María José Molina García, «Evolución de la libre circulación de personas en el marco de la ciudadanía de la Unión Europea: ¿son la normativa y la jurisprudencia comunitaria suficientes garantes del ejercicio de esta libertad?», Actualidad civil, n. ${ }^{\circ} 5$, (2015): 8.

22 STJUE de 13 de julio de 2017, E., as. C-193/16, FD. 18 y jurisprudencia allí citada.

23 STJCE de 26 de febrero de 1975, Bonsignore, as. C-67/74.

${ }^{24}$ STJCE de 19 de enero de 1999, Calfa, as. C-384/96.

25 STJCE de 22 de mayo de 1980, Mario Santillo, as. C-131/79.

${ }^{26}$ STJCE de 24 de abril de 2004, Orfanopoulos y Oliveri, as. C-482/01. 
impone los límites al ejercicio de este derecho fundamental y no el Derecho de cada Estado miembro. Ello se debe a que, tales límites deben responder a los objetivos de interés general reconocidos por la Unión Europea para proteger aspectos públicos ${ }^{27}$.

De lo anterior puede desprenderse que las disposiciones de la Directiva 2004/38, relativa al derecho de los ciudadanos de la Unión y de los miembros de su familia a circular y residir libremente en el territorio de los Estados miembros, ni deben interpretarse de manera restrictiva, ni tampoco tienen que ser privadas de su efecto útil ${ }^{28}$. Ante esta situación cabe plantearse si el cónyuge del mismo sexo de un ciudadano de la Unión Europea y nacional de un tercer Estado, que acompaña a dicho ciudadano en el territorio de otro Estado miembro, puede ser beneficiario de un derecho de residencia en ese país por un período superior a tres meses.

\section{El concepto de «cónyuge» en el marco de la Directiva 2004/38, relativa al derecho de los ciudadanos de la Unión y de los miembros de su familia a circular y residir libremente en el territorio de los Estados miembros}

A efectos de la presente Directiva, se entenderá por «miembro de la familia» (art. 2.2 Directiva 2004/38): a) el cónyuge; b) la pareja con la que el ciudadano de la Unión Europea ha celebrado una unión registrada, con arreglo a la legislación de un Estado miembro, pero únicamente en el supuesto de que la legislación del Estado miembro de acogida otorgue a las uniones registradas un trato equivalente a los matrimonios y de conformidad con las condiciones establecidas en la legislación aplicable del Estado miembro de acogida; c) los descendientes directos menores de veintiún años o a cargo y los del cónyuge o de la pareja definida con anterioridad; d) los ascendientes directos a cargo y los del cónyuge o de la pareja definida anteriormente.

En lo que interesa al presente trabajo, cabe plantearse si, en el contexto del derecho de los ciudadanos de la Unión Europea y de los miembros de su familia a circular y residir libremente en el territorio de los Estados miembros, la noción de «cónyuge» incluye a las personas homosexuales.

27 STJUE de 4 de junio de 2013, ZZ, as. C-300/11.

28 Vid. STJUE de 5 de junio de 2018, Coman y Hamilton, as. C-673/16. El Tribunal señala que las disposiciones que establecen la libre circulación de los ciudadanos de la Unión, tal y como sucede con la Directiva 2004/38, deben interpretarse en sentido amplio porque aquélla es uno de los fundamentos de la Unión Europea. 
Del tenor literal de la disposición puede desprenderse que la Directiva, en el caso de la unión registrada, se remite expresamente a lo establecido en la legislación del Estado miembro de acogida. Por tanto, el concepto de «unión registrada» se determinará con arreglo a lo previsto en dicho ordenamiento jurídico. Ello trae como consecuencia que cada Estado miembro de la Unión Europea está facultado para decidir sobre si es posible, o no, la celebración de una unión civil en su país, los derechos que dicha unión civil otorga a la pareja y si cabe, o no, el reconocimiento de una unión civil válidamente contraída en otro Estado miembro.

Así las cosas, los efectos jurídicos que derivan de una unión registrada pueden ser distintos, atendiendo al país de celebración. Sirva como ejemplo que no todos los Estados miembros de la Unión Europea reconocen a las uniones registradas los mismos derechos en cuanto al régimen matrimonial y/o a la pensión de alimentos y que, en algunos Estados miembros, las uniones civiles y registradas se consideran equivalentes a la institución jurídica del matrimonio.

A diferencia de ello, la Directiva 2004/38 no realiza esta precisión respecto a la definición de «cónyuge». Si el concepto de «cónyuge»se definiera con arreglo a lo dispuesto en el ordenamiento jurídico del Estado de acogida, la obtención de un permiso de residencia dependería de si es posible, o no, reconocer el matrimonio homosexual en virtud de las normas de ese Estado.

Ante esta situación, el Tribunal de Justicia de la Unión Europea señala que, en el supuesto de que una disposición del Derecho de la Unión Europea no se remita expresamente al ordenamiento jurídico de los Estados miembros para determinar su sentido y alcance, dicha disposición debe ser objeto de una interpretación autónoma y uniforme en toda la Unión Europea ${ }^{29}$. Para ello, el operador jurídico no sólo debe tomar en consideración el tenor literal de la disposición, sino también el contexto en el que ésta se circunscribe y los objetivos perseguidos por la norma de la que forma parte ${ }^{30}$.

En sintonía con lo anterior, el Tribunal de Justicia es la institución que ha ido perfilando el concepto de «cónyuge» porque éste no se encuentra recogido en el Derecho de la Unión Europea ${ }^{31}$. El punto de partida puede situarse en la interpretación que dicho Tribunal realiza de lo

29 Vid.por todas la STJUE de 18 de octubre de 2016, Nikiforidis, as. C-135/15, FD. 28 y jurisprudencia allí citada.

30 STJUE de 27 de septiembre de 2017, Nintendo, as. C-24/16 y C-25/16, FD. 70.

${ }^{31}$ Millán Requena Casanova, «Libre circulación de los matrimonios del mismo sexo celebrados en el territorio de la Unión Europea: consecuencias del asunto Coman y otros», $R e$ vista de Derecho Comunitario Europeo, n. ${ }^{\circ} 62$ (2019): 41-79, esp. 58. 
dispuesto en el artículo 10 del Reglamento 1612/68, sobre la libre circulación de trabajadores ${ }^{32}$ : los trabajadores únicamente se desplazarán de un Estado miembro a otro si los miembros de su familia pueden acompañarlos. Por tanto, determinados familiares del trabajador - entre ellos su cónyuge - pueden disfrutar del derecho a la libre circulación y residencia en el territorio de los Estados miembros de la Unión Europea, aunque a título derivado.

En particular, en el asunto Reed, el Tribunal de Justicia afirma, en relación con el Reglamento indicado con anterioridad, que el concepto de «cónyuge» solamente puede encajar en una relación fundada en el matrimonio, sin posibilidad de ampliarlo a una relación de pareja estable. La razón en la que el Tribunal de Justicia fundamenta la afirmación anterior es que, en ese momento, no existe «una evolución social de orden general que justifique una interpretación extensiva [de la noción de «cónyuge»]»33.

De ello puede desprenderse que el concepto de «cónyuge» ostenta un carácter dinámico porque su delimitación depende de una eventual evolución de la sociedad y de la postura que defiendan, en conjunto, los Estados miembros de la Unión Europea. Esta situación encuentra justificación en el hecho objetivo de que el Derecho de la Unión Europea debe interpretarse con arreglo a las circunstancias existentes en la actualidad porque el Derecho no puede «aislarse de la sociedad tal cual es, sino que debe adaptarse a ella lo antes posible» ${ }^{34}$.

En este sentido, el Abogado General -el Sr. Melchior Watheleten el asunto Coman $^{35}$, advierte que, en el marco en el que se desarrolla la Directiva 2004/38, relativa al derecho de los ciudadanos de la Unión Europea y de los miembros de sus familias a circular y a residir libremente en el territorio de los Estados miembros, el hecho de que el concepto de «cónyuge» incluya a la persona homosexual no afecta a la decisión unilateral de cada Estado miembro a la hora de permitir, o no, la válida celebración en su territorio de matrimonios entre personas del

${ }^{32}$ Reglamento (CEE) 1612/68, relativo a la libre circulación de trabajadores por cuenta ajena dentro de la Comunidad (DOCE L 257, de 19 de octubre de 1968), derogado por el Reglamento 492/2011, relativo a la libre circulación de trabajadores dentro de la Unión Europea (DOCE L 141, de 5 de abril de 2011).

33 STJCE de 17 de abril de 1986, Reed, as. 59/85, FD. 15.

34 Así lo han indicado distintos Abogados Generales en diferentes asuntos. Valgan como ejemplos, entre otras, las Conclusiones del Abogado General Wahl, presentadas en el asunto Haralambidis (as. C-270/13), las Conclusiones del Abogado General Szpunar presentadas en el asunto McCarthy (as. C-202/13) o las Conclusiones del Abogado General Geelhoed, presentadas en el caso Baumbast (as. C-413/99).

35 Vid. STJUE de 5 de junio de 2018, Coman y Hamilton, as. C-673/16. 
mismo $\operatorname{sexo}^{36}$. Sin embargo, lo que sí parece claro es que la noción de «cónyuge» remite a la institución jurídica del matrimonio, con independencia del género, del lugar y del momento en el que éste se haya contraído ${ }^{37}$.

La neutralidad de género respecto de la palabra «cónyuge», escogida por esta Directiva, presenta un marcado carácter deliberado ${ }^{38}$. Esta afirmación encuentra sentido en que la Comisión ya utilizó dicho término en la Propuesta de la Directiva, del Parlamento Europeo y de Consejo, relativa al derecho de los ciudadanos de la Unión Europea y de los miembros de su familia a circular y residir libremente en el territorio de los Estados miembros $^{39}$.

A ello hay que añadir que, en particular, el Informe del Parlamento Europeo, de 23 de enero de 2003, sobre la Propuesta de la Directiva, defendía que la misma se refiriera explícitamente a la indiferencia del sexo de la persona a través de la expresión «independientemente de su sexo, conforme a la correspondiente legislación nacional». La justificación de la anterior afirmación era que «la legislación de la Unión Europea relativa a la libre circulación debía reflejar y respetar la diversidad de relaciones familiares existente en la sociedad actual» ${ }^{40}$.

No obstante, el Consejo de la Unión Europea mostró su disconformidad con la proposición realizada por el Parlamento Europeo, fundamentando ésta en que, en ese momento, únicamente dos Estados miembros de la Unión Europea - el Reino de Bélgica y el Reino de los Países Bajoscontaban con una norma que permitía la válida celebración del matrimonio entre personas del mismo sexo ${ }^{41}$. Por tanto, se restringe la noción de «cón-

36 Marko Ilesic, «Concepto de «cónyuge» en un matrimonio entre personas del mismo sexo a los efectos del derecho a circular y residir libremente en el territorio de los Estados miembros: TJ, Gran Sala, S 5 Jun. 2018. Asunto C-673: Coman y otros», La Ley Unión Europea, . $^{\circ} 61$ (2018): versión on line.

En contra de que la noción de «cónyuge» sea interpretada de manera autónoma en toda la Unión Europea, puede encontrarse el trabajo de Marta Requejo Isidro, «DIPr. de la familia y libre circulación de trabajadores: reflexiones suscitadas por el matrimonio homosexual», La UE ante el siglo XXI: los retos de Niza, XIX Jornadas de la AEPDIRI, (2003): 243-251, esp. 245.

37 STJUE de 25 de julio de 2008, Metock y otros, as. C-127/08, FD. 98 y 99.

38 Santiago Soldevila Fragoso, «Matrimonio homosexual y derecho de residencia en la Unión Europea», Actualidad Administrativa, n. ${ }^{\circ} 7$ (2018): versión on line.

39 [COM] (2001) 257 final, DO 2001, C 270 E, p. 150.

40 Enmienda 14, adoptada el 23 de enero de 2003, PE 319.238, Documento de sesión A5-0009/2003.

${ }^{41}$ María Elena Zabalo Escudero y María del Pilar Diago Diago, «Matrimonio entre personas del mismo sexo: perspectiva internacional privatista», Estudios de derecho judicial, n. ${ }^{\circ} 130$ (2007): 245-310. 
yuge» al de distinto sexo, a la espera de una evolución social futura, tal y como se indicó anteriormente ${ }^{42}$.

Sin embargo, en la actualidad, la situación es muy distinta. Desde 2004, doce Estados miembros se han sumado a los dos originarios, permitiendo en sus países la válida celebración de matrimonios entre personas del mismo sexo. En particular, pueden concretarse, por orden cronológico, en los siguientes ${ }^{43}$ : España, Suecia, Portugal, Dinamarca, Francia, Reino Unido (a excepción de Irlanda del Norte), Luxemburgo, Irlanda, Finlandia, Alemania, Malta y Austria.

En otro orden de cosas, la interpretación de la disposición objeto de estudio debe realizarse atendiendo asimismo al contexto y a los objetivos perseguidos por la normativa de la que forma parte, tal y como se indicó con anterioridad.

En relación con el contexto, la noción de «cónyuge» se encuentra estrechamente vinculada con el respeto al derecho a la vida privada y familiar ${ }^{44}$. El Convenio Europeo de Derechos Humanos y la Carta de Derechos Fundamentales de la Unión Europea señalan que toda persona tiene derecho al respeto de su vida privada y familiar, de su domicilio y de sus comunicaciones (art. 7 CDFUE y art. 8 CEDH, respectivamente) ${ }^{45}$.

Esta situación se ve reforzada por el hecho objetivo de que los instrumentos legales estatales, europeos e internacionales, tales como el Convenio Europeo de Derechos Humanos ${ }^{46}$ y la Carta de Derechos Fundamentales de la Unión Europea ${ }^{47}$, reconocen expresamente que el derecho a contraer matrimonio y el derecho a fundar una familia - de conformidad con lo previsto en las Leyes nacionales que regulan el ejercicio de este

42 Bertrand Ancel y Horatia Muir Watt, « La désunion européenne : le Règlement dit Bruxelles II», Revue Critique de Droit International Privé, (2001) : 403-457, esp. 408.

43 Alicia Rivas Vañó, «Matrimonio y orientación sexual: la fuerza expansiva del derecho a la no discriminación. Comentario de las Sentencias Tadeucci y Coman», Lex Social. Revista Jurídica de los Derechos Sociales, n. ${ }^{\circ} 1$ (2019): 136-161, esp. 139

44 STJCE de 7 de julio de 1992, Singh, as. C-370/90, FD. 21 y 23.

45 El Cons. 31 de la Directiva 2004/38 afirma: «La presente Directiva respeta los derechos y libertades fundamentales y observa los principios reconocidos, en particular, por la Carta de Derechos Fundamentales de la Unión Europea. De conformidad con la prohibición de discriminación [...], los Estados miembros deben aplicar las disposiciones de la misma sin discriminar entre los beneficiarios [...] por razones como el sexo, raza, color, origen étnico o social, características genéticas, lengua, religión o convicciones, opiniones políticas o de otro tipo, pertenencia a una minoría nacional, patrimonio, nacimiento, discapacidad, edad u orientación sexual».

46 Artículo $12 \mathrm{CEDH}$ : «A partir de la edad núbil, el hombre y la mujer tienen derecho a casarse y a fundar una familia según las leyes nacionales que rijan el ejercicio de este derecho».

47 Artículo 9 CDFUE: «Se garantizan el derecho a contraer matrimonio y el derecho a fundar una familia según las leyes nacionales que regulen su ejercicio». 
derecho - constituye un derecho fundamental. Ahora bien, la institución jurídica del matrimonio incide directamente en el desarrollo personal y social del individuo y la homosexualidad es un rasgo íntimamente ligado a ellos ${ }^{48}$, lo que permite fortalecer el libre desarrollo de la afectividad y de la sexualidad ${ }^{49}$. En consecuencia, el libre desarrollo de la personalidad garantiza el pleno cumplimiento de los derechos fundamentales, lo que cobra sentido cuando el matrimonio se reconoce también a las personas homosexuales ${ }^{50}$.

En este sentido, el Tribunal Europeo de Derechos Humanos considera que la orientación sexual no es una razón que impida a la pareja disfrutar de una auténtica vida familiar. Las parejas del mismo sexo y las parejas de sexo distinto pueden disfrutar, de igual manera, de una vida familiar plena. En consecuencia, el Tribunal Europeo de Derechos Humanos crea un nuevo concepto de «vida familiar», más moderno, que no se circunscribe, en exclusiva, a las relaciones basadas en el matrimonio, sino que incluye también otras ${ }^{51}$. Por este motivo, el Tribunal Europeo de Derechos Humanos considera que debe existir la posibilidad de ofrecer a las personas homosexuales la obtención de un reconocimiento legal y de una protección jurídica de su pareja ${ }^{52}$.

En esta línea de pensamiento, una diferencia de trato basada, en exclusiva, en criterios propios de la orientación sexual, no puede aceptarse desde la perspectiva de lo establecido en la Carta de Derechos Fundamentales de la Unión Europea y en el Convenio Europeo de Derechos Humanos. La finalidad de proteger jurídicamente la institución legal del matrimonio no puede legitimar una discriminación, únicamente, por motivos de orientación sexual.

En consecuencia, la evolución social que ha sufrido el derecho al respeto a la vida privada y familiar conduce a interpretar la noción de «cónyuge» sin tomar en consideración el sexo de las personas, a los solos efectos de la Directiva 2004/38, relativa al derecho de los ciudadanos de la Unión Europea y de los miembros de sus familias a circular y a residir libremente en el territorio de los Estados miembros. Sólo de esta manera se garantiza, de un lado, el respeto al derecho a la vida privada y familiar tal

48 Fernando Rey Martínez, «Homosexualidad y Constitución», Revista Española de Derecho Constitucional, . $^{\circ} 73$ (2005): 137.

49 Octavio Salazar Benítez, «Derecho al matrimonio y diversidad familiar», UNED: Revista de Derecho Político, . $^{\circ} 86$ (2013): 200.

50 María Martín Sánchez, «Los derechos de las parejas del mismo sexo en Europa. Estudio comparado», Revista Española de Derecho Constitucional, n. ${ }^{\circ} 107$ (2016): 219-253.

51 STEDH de 13 de julio de 2000, Elsholz c. Alemania.

52 STEDH de 21 de julio de 2015, Oliari y otros c. Italia, FD. 185. 
y como se recoge en la Carta de Derechos Fundamentales de la Unión Europea y en el Convenio Europeo de Derechos Humanos y, de otro lado, se asegura la libertad de cada Estado miembro a la hora de decidir si la celebración del matrimonio entre personas del mismo sexo en su territorio será válida, o no.

Respecto al objetivo que pretende alcanzar la Directiva 2004/38, éste consiste en facilitar el derecho de los ciudadanos de la Unión Europea y de los miembros de sus familias a circular y a residir libremente en el territorio de los Estados miembros, cuyos parámetros fueron descritos en el epígrafe anterior (vid. también en este sentido el art. 21.1 TFUE). En este sentido, sólo una interpretación del concepto de «cónyuge» que no tenga en cuenta su orientación sexual es la que facilita el ejercicio de tal derecho.

No obstante lo anterior, existe un ámbito en el Derecho de la Unión Europea en el que la noción de «cónyuge» debe interpretarse de manera autónoma: la función pública. Ello se debe a que el ámbito de la función pública permite al Derecho de la Unión Europea avanzar sin restricciones porque no rige el principio de subsidiariedad ni existen limitaciones derivadas de la protección del orden público de los Estados miembros ${ }^{53}$. El Estatuto de Funcionarios de la Unión Europea introdujo en 2004 dos novedades respecto del anterior, en el que cabe destacar, en lo que interesa al presente trabajo, que el concepto de «cónyuge de funcionario de las Comunidades Europeas» incluye al homosexual ${ }^{54}$.

\section{Matrimonio entre personas del mismo sexo y Derecho internacional privado de la Unión Europea}

La celebración del matrimonio entre personas del mismo sexo no se admite en todos los Estados miembros de la Unión Europea, tal y como se indicó con anterioridad. El punto de partida se sitúa en el hecho objetivo de que el ámbito relativo al estado civil de las personas físicas es competencia de cada Estado miembro ${ }^{55}$. En este sentido, cada Estado miembro de la Unión Europea es libre para decidir si la celebración de un matrimonio entre personas del mismo sexo, en su territorio, es válida y surte efectos jurídicos, o no. Por ejemplo, en España, las parejas homosexuales pueden con-

53 Mercedes Soto Moya, Uniones transfronterizas entre personas del mismo sexo, (Valencia: Tirant lo Blanch, 2013), 154.

${ }^{54}$ Reglamento 723/2004, de 22 de marzo, por el que se modifica el Estatuto de Funcionarios de las Comunidades Europeas y el régimen aplicable a otros agentes de las Comunidades Europeas (DOCE L 124, de 27 de abril de 2004).

55 STJUE de 12 de diciembre de 2013, Hay, as. C-267/12, FD. 26. 
traer válido matrimonio entre sí, en nuestro país, desde que entró en vigor la Ley 13/2005, de 1 de julio, por la que se modificó el Código Civil en materia de derecho a contraer matrimonio ${ }^{56}$.

Ello se debe, entre otros factores, a que los Tratados de la Unión Europea prevén que la Unión Europea debe respetar la identidad nacional de cada Estado miembro, inherente a las estructuras fundamentales políticas y constitucionales, también en lo referente a la autonomía local y regional y, asimismo, tiene que respetar las funciones esenciales de cada Estado miembro, en especial, las que tienen por objeto garantizar su integridad territorial, mantener el orden público y salvaguardar la seguridad nacional (art. 4.2 TUE). Sirva como ejemplo que en Bulgaria, Lituania, Polonia, Letonia, Rumanía y Eslovaquia no se permite la celebración de matrimonios entre personas del mismo sexo ni se reconocen los efectos jurídicos de los que se hayan contraído válidamente en otro Estado miembro de la Unión Europea.

Ahora bien, el principio de respeto a la identidad nacional de cada Estado miembro no opera con carácter absoluto, sino que convive con el principio de cooperación leal, recogido expresamente en el Tratado de la Unión Europea. En virtud de éste, los Estados miembros y la Unión Europea colaborarán en el cumplimiento de los objetivos previstos en los Tratados. Para ello, los Estados miembros adoptarán todas las medidas, generales o específicas, apropiadas para garantizar el cumplimiento de las obligaciones derivadas de los Tratados y, paralelamente, se abstendrán de adoptar cualquier medida que pueda poner en peligro la consecución de los objetivos de la Unión Europea (art. 4.3 TUE). En lo que interesa al presente trabajo, entre los objetivos de la Unión Europea cabe citar, la creación de un auténtico espacio de libertad seguridad y justicia, sin fronteras interiores e inspirado en el principio de no discriminación, en el que esté garantizada la libre circulación de personas (art. 3.2 TUE).

En este contexto, el ámbito relativo al estado civil de las personas físicas - que es competencia de cada Estado miembro - se encuentra intrínsecamente relacionado con el derecho fundamental a la libre circulación y residencia en la Unión Europea - que es uno de los principales objetivos

56 Santiago Álvarez González, «Dimensión internacional del matrimonio entre personas del mismo sexo: lo que el ojo del legislador español no vio», en Estudios del Derecho de Familia y Sucesiones, ed. por Santiago Álvarez González (Santiago de Compostela: Fundación Asesores Locales, 2009), 9-39, esp. 11. El autor expone que la Ley 13/2005 no ha regulado, de manera específica, ninguna cuestión que incida en la disciplina de Derecho internacional privado. Por tanto, las normas de Derecho internacional privado españolas previstas para el matrimonio heterosexual, resultarán también aplicables al matrimonio homosexual, con las dificultades que de por sí plantean. 
de la Unió- ${ }^{57}$. Ante esta situación, cabe plantearse si es posible (con arreglo a qué criterios y en qué medida) que el Estado miembro de acogida restrinja el derecho fundamental de los ciudadanos de la Unión Europea y de los miembros de su familia a circular y residir libremente en el territorio de los Estados miembros, en el caso de matrimonios entre personas del mismo sexo, prohibidos por la legislación del Estado miembro de acogida.

\section{La regla de reconocimiento y su ámbito jurídico de actuación: dimensión patrimonial vs. dimensión humana}

El principio de mutuo reconocimiento implica que una situación jurídica válidamente creada en la Unión Europea o una resolución judicial o extrajudicial dictada por la autoridad de un Estado miembro de la Unión Europea sea tratada como si se hubiera celebrado en el Estado miembro en el que se solicita su reconocimiento. Este principio de reconocimiento mutuo encuentra su origen, fundamentalmente, en el sector de la industria y de los servicios y surge con el objetivo de potenciar la libre circulación de mercancías y de servicios en los territorios de los Estados miembros de la Unión Europea, sin que resulte necesario acudir a la armonización de las legislaciones nacionales en estos ámbitos ${ }^{58}$. Sirva como ejemplo, la clásica sentencia Cassis de Dijon, en la que el pronunciamiento del Tribunal de Justicia refleja un claro intento de agilizar la libre circulación de mercancías ${ }^{59}$.

En consecuencia, el origen del principio de reconocimiento mutuo presenta un marcado carácter patrimonial frente al escaso desarrollo de su dimensión humana y social. Sin embargo, en un momento ulterior, esta situación cambia. El principio de mutuo reconocimiento de situaciones jurídicas creadas en la Unión Europea se desarrolla como expresión de la libre circulación de factores productivos y, especialmente, de la libre circulación de personas.

Ello se refleja en los textos legales de la Unión Europea que se pronuncian sobre el principio de mutuo reconocimiento en el ámbito civil, mercantil y de la familia y, también, en el hecho de que el Tribunal de Justi-

57 STJUE de 8 de noviembre de 2012, Iida, as. C-40/11, FD. 72.

58 Comunicación de la Comisión «El reconocimiento mutuo en el marco del seguimiento del Plan de acción para el Mercado Interior» [COM (1999) 299 final — no publicada en el Diario Oficial], p. 2.

59 STJCE de 20 de febrero de 1979, Rewe / Bundesmonopolverwaltung für Branntwein, as. C-120-78, se refiere, indirectamente, al principio de mutuo reconocimiento al señalar en el FD 14: «...los preceptos relativos al grado alcohólico mínimo de las bebidas espirituosas no persiguen un objetivo de interés general que pueda prevalecer sobre las exigencias de la libre circulación de mercancías, que constituye una de las normas fundamentales de la Comunidad». 
cia extiende su aplicación a materias muy concretas, tales como, el nombre y apellidos de las personas físicas y las sociedades. Valgan como ejemplo, entre otros, en el ámbito relativo al «nombre y apellidos de la persona física», los asuntos Konstantinidis ${ }^{60}$, García Avelló ${ }^{61}$, Grunkin-Paul ${ }^{62}$, Wittgenstein $^{63}$ y $\operatorname{Vardyn}^{64}$. En materia de sociedades, cabe hacer referencia, entre otros, a los supuestos Centros ${ }^{65}$, Überseering ${ }^{66}$, Inspire Art ${ }^{67}$ y Cadbury Schweppes plc ${ }^{68}$.

En sintonía con lo anterior, el principio de mutuo reconocimiento posibilita que toda situación jurídica legalmente creada en un Estado miembro de la Unión Europea, sea considerada una situación jurídica válida y existente en los demás Estados miembros de la Unión Europea, con independencia de la Ley estatal que la autoridad del Estado miembro de origen aplicó para crear dicha situación jurídica y siempre que se respeten los principios fundamentales que integran el orden público internacional del Estado miembro de acogida ${ }^{69}$.

La situación jurídica creada en el Estado miembro de origen se exporta, tal cual, al Estado miembro de acogida para que la autoridad de éste conceda el reconocimiento a esa situación jurídica, pero sólo si procede ${ }^{70}$. Por tanto, la autoridad del Estado miembro de origen ya conoció la situación, le aplicó la normativa pertinente y la dotó de los efectos propios derivados de

60 Sentencia TJCE 30 marzo 1993, Christos Konstantinidis contra Stadt Altensteig Standesamt y Landratsamt Calw - Ordnungsamt, as. C-168/91.

61 STJUE 2 octubre 2003, Carlos Garcia Avello contra Estado belga, as. C-148/02.

62 STJUE 14 octubre 2008, Stefan Grunkin y Dorothee Regina Paul, as. C-353/06.

${ }^{63}$ STJUE 22 diciembre 2010, Ilonka Sayn-Wittgenstein contra Landeshauptmann von Wien, as. C-208/09.

${ }^{64}$ STJUE 12 mayo 2011, Malgožata Runevič-Vardyn y Łukasz Pawet Wardyn contra Vilniaus miesto savivaldybès administracija y otros, as. C-391/09.

65 STJCE 9 marzo 1999, Centros Ltd contra Erhvervs- og Selskabsstyrelsen, as. C-212-97.

${ }^{66}$ STJCE 5 noviembre 2002, Überseering BV contra Nordic Construction Company Baumanagement GmbH (NCC), as. C-208/00.

67 STJCE 30 septiembre 2003, Kamer van Koophandel en Fabrieken voor Amsterdam contra Inspire Art Ltd, as. C-167/01.

${ }^{68}$ STJUE 12 septiembre 2006, Cadbury Schweppes plc y Cadbury Schweppes Overseas Ltd contra Commissioners of Inland Revenue, as. C-196/04.

69 Proyecto de medidas para la aplicación del principio de mutuo reconocimiento de las resoluciones judiciales en materia civil y mercantil, de fecha 15 enero 2001 (DOCE C 12, de fecha 15 enero 2001). Véase también en relación con este la interpretación de este Proyecto, el trabajo de Cristina González Beilfuss, «El Proyecto de medidas para la aplicación del principio de mutuo reconocimiento de las resoluciones judiciales en materia civil y mercantil», Revista Española Derecho Internacional, n. ${ }^{\circ} 2$ (2000): 662-669.

${ }^{70}$ Erik Jayme, «Il diritto internazionale privato nel sistema comunitario e i suoi recenti sviluppi normativi nei rapporti con Stati terzi», Rivista di Diritto Internazionale Privato $e$ Processuale, n. 2 (2006): 353-360, esp. 360. 
la misma ${ }^{71}$. De este modo, la autoridad del Estado miembro de destino no tiene que entrar a valorar la Ley estatal que aplicó la autoridad del Estado miembro de origen, ni debe aplicar su norma de conflicto de leyes a dicha situación jurídica, ni tampoco puede concederle efectos jurídicos distintos de los que adquirió ${ }^{72}$.

Únicamente debería limitarse, en su caso, a reconocer la situación jurídica legalmente creada en la Unión Europea y no tendría que rechazar el reconocimiento de tal situación jurídica por el solo hecho de que la norma de conflicto de leyes que aplicó la autoridad del Estado miembro de origen sea distinta de la que al mismo supuesto habría aplicado la autoridad del Estado miembro de destino ${ }^{73}$.

En consecuencia, el principio de mutuo reconocimiento puede encontrar su fundamento en la confianza que la autoridad del Estado miembro de acogida deposita en la decisión sobre la que se pronunció la autoridad del Estado miembro de origen, que acepta y reconoce como válida esa situación jurídica ${ }^{74}$. Esta situación arranca de la idea de respeto a la Justicia que han impartido los tribunales de un Estado de la Unión Europea y de respeto al trabajo que desempeñan las autoridades públicas de cualquier Estado miembro de la Unión Europea. Además, esta regla de reconocimiento de situaciones jurídicas privadas que ostentan un carácter internacional presenta numerosas ventajas, entre las que cabe destacar la coherencia internacional en las situaciones jurídicas privadas, lo que proporciona continuidad en el espacio y seguridad jurídica internacional.

No obstante, en la actualidad, existe un elevado número de materias sobre las que el Tribunal de Justicia no se ha pronunciado expresamente y cuyo reconocimiento podría resultar controvertido en los Estados miembros de la Unión Europea. Por esta razón, debe cuestionarse si el mutuo reconocimiento debería aplicarse respecto de cualquier situación jurídica pri-

71 Dominique Carreau, Paul Lagarde y Hervé Synvet, « La reconnaissance des noms patronymiques», Répertoire de Droit International Dalloz, (janvier 2009) : 13-15.

72 Francisco José Garcimartín Alférez e Iván Heredia Cervantes, «Acceso a los registros españoles de resoluciones judiciales extranjeras en el marco europeo», La Ley Unión Europea, n. ${ }^{\circ} 6$ (2013): 1-31, esp. 4.

73 Marta Del Pozo Pérez, «La orden europea de detención y entrega: un avance del principio de reconocimiento mutuo de resoluciones judiciales entre los Estados de la Unión Europea», La Ley: Revista Jurídica Española de Doctrina, Jurisprudencia y Bibliografía, n. ${ }^{\circ} 1$, (2005): 1551-1568, esp. 1554.

${ }^{74}$ Marina Joya Carrasco, «Reconocimiento y ejecución de resoluciones extranjeras en la Unión Europea. Del Convenio de Bruselas de 1968 al Reglamento (UE) 1215/2012, del Parlamento Europeo y del Consejo, de 12 de diciembre de 2012», Diario La Ley, n. ${ }^{\circ} 8247$ (2014): 1-13, esp. 2 «La Unión Europea crea un derecho aplicable directamente a todos los Estados miembros fundamentándose en los principios de reconocimiento mutuo, cooperación horizontal entre Estados y confianza recíproca». 
vada internacional válida y legalmente creada en un Estado miembro de la Unión Europea, con independencia de que el Tribunal de Justicia se haya pronunciado expresamente, o no, sobre ello y de la materia que trate. En lo que interesa al presente trabajo, se plantea si el principio de mutuo reconocimiento debe operar respecto de la celebración de matrimonios entre personas del mismo sexo.

\section{El reconocimiento de los matrimonios celebrados entre personas del} mismo sexo y el derecho a circular y residir libremente en el territorio de los Estados miembros de la Unión Europea

La válida celebración de matrimonios entre personas del mismo sexo en el territorio de los Estados miembros de la Unión Europea no constituye, en absoluto, un fenómeno aislado. Sin embargo, esta situación no es posible en todos ellos, lo que encuentra justificación en el hecho objetivo de que cada Estado miembro de la Unión Europea posee una identidad social y cultural propia, que puede ser distinta de la de los demás Estados miembros de la Unión Europea, tal y como se puso de relieve con anterioridad.

En este contexto, un nacional de un Estado miembro de la Unión Europea puede estar casado sólo en algunos Estados miembros - los que admitan la válida celebración del matrimonio homosexual en su territorio y/o el reconocimiento de aquél que se haya celebrado en el extranjero - pero no en otros - los que prohíban expresamente su celebración y/o su reconocimiento.

Este hecho puede traer como consecuencia que los matrimonios del mismo sexo celebrados en España sean uniones claudicantes en los países de origen de los cónyuges que no hayan previsto una regulación al respecto o que establezcan un régimen jurídico distinto. Ello afecta, a su vez, necesariamente, al derecho fundamental de los ciudadanos de la Unión Europea y de los miembros de su familia a circular y residir libremente en el territorio de los Estados miembros ${ }^{75}$. La razón es que esta situación desincentiva a los ciudadanos de la Unión y a los miembros de su familia a ejercitar tal derecho porque desplazarse de un Estado miembro a otro puede implicar un cambio de su estado civil ${ }^{76}$.

75 Mercedes Soto Moya, Uniones transfronterizas entre personas del mismo sexo, (Valencia: Tirant lo Blanch, 2013), 28.

${ }^{76}$ Dieter Martiny, «Is unification of Family Law Feasible or Even Desirable?», en Towards a European Civil Code, ed. por Arthur S. Hartkamp (The Hague/London/Boston: Kluwer Law International, 2011), 429-459. 
Desde este postulado, el derecho fundamental a la libre circulación y residencia de los ciudadanos de la Unión Europea y de los miembros de su familia en el territorio de los Estados miembros no sólo debería significar el ejercicio del derecho al desplazamiento sin obstáculos físicos, sino que también tendría que integrar «la libre circulación del estado civil», entendida como circunstancia que acompaña a la persona ${ }^{77}$.

Ahora bien, esta situación sólo sería posible si la institución del matrimonio se rigiera, en toda la Unión Europea, por el principio de unicidad de estado civil. De esta manera, una situación jurídica válidamente creada en un Estado miembro, tal y como sería la celebración de un matrimonio homosexual, tendría continuidad en el espacio ${ }^{78}$, lo que se refuerza en el contexto del Derecho de la Unión Europea, por las exigencias que derivan de la libre circulación de personas que instaura el Tratado ${ }^{79}$.

Sin embargo, la realidad es muy distinta: existen dos modalidades de matrimonio que pueden concretarse en los que son válidos en el marco de la Unión Europea y los que lo son a nivel estatal, por la única razón de la diferencia de sexo. En este sentido, en la práctica, la negativa del Estado miembro de acogida a reconocer el matrimonio homosexual válidamente celebrado en otro Estado miembro de la Unión Europea podría incentivar el mantenimiento de dos relaciones formalizadas paralelas que se distinguirían sólo por el sexo del cónyuge ${ }^{80}$. De ello puede desprenderse que esta realidad da lugar a una discriminación fundamentada en la orientación sexual, lo que se encuentra expresamente prohibido en el artículo 21 de la Carta de Derechos Fundamentales de la Unión Europea ${ }^{81}$.

Ante esta situación, debe valorarse si, una discriminación basada en la orientación sexual puede obligar a los Estados miembros de la Unión Europea a reconsiderar la institución jurídica del matrimonio, respecto del ejercicio del derecho a la libre circulación y residencia. Ello no es baladí porque la respuesta permitirá, o no, que el nacional de un tercer Estado que contrae válido matrimonio homosexual con otro ciudadano de la Unión Europea pueda acompañarlo, en el caso de que, por cualquier motivo que cubra sus intereses, ambos decidan trasladar su residencia de un Estado miembro a otro.

77 Paul Lagarde, « Développements futurs du droit international privé dans une Europe en voie d'unification: quelques conjectures», RabelsZ (2004) : 225-243, esp. 231.

78 Jürgen Basedow, «Souveraineté teeritoriale et globalisation des marchés : le domaine d'application des lois contre les restrictions de la concurrence», RCADI, n. ${ }^{\circ} 264$ (1997) : 9-177, esp. 171.

79 Cristina González Beilfuss, Parejas de hecho y matrimonios del mismo sexo en la Unión Europea, (Madrid: Marcial Pons, 2004), 62.

${ }^{80}$ Hans Ulrich Jessurun d'Oliveira, «Registered Partnerships, PACSes and Private International Law: some reflexions », RDIPP, n. ${ }^{\circ} 2$ (2000), 293-322, p. 319.

${ }^{81}$ STJUE de 24 de noviembre de 2016, Parris, as. C-443/15, FD. 58. 
En consecuencia, el hecho de que el Estado miembro de acogida no considere cónyuges a dos personas del mismo sexo que han contraído válido matrimonio en otro Estado miembro, a los solos efectos de entrada y residencia, provoca graves restricciones a la libre circulación de personas. Ahora bien, las autoridades de un Estado miembro de la Unión Europea no pueden ser obligadas a admitir el reconocimiento de una situación jurídica que no sintoniza correctamente con su identidad y organización social y cultural, siempre, claro está, que puedan fundamentarse jurídicamente los motivos de tal denegación.

En este contexto, el legislador de cada Estado miembro de la Unión Europea puede adoptar medidas que comporten un obstáculo a la libre circulación y residencia si éstas se aplican de manera no discriminatoria, si están justificadas por razones imperiosas de interés general y si son medidas adecuadas para garantizar la realización del objetivo que persiguen, siempre que no vaya más allá de lo que sea estrictamente necesario para alcanzarlo.

Por ello, un obstáculo al ejercicio del derecho fundamental a la libre circulación en la Unión Europea puede justificarse en el supuesto de que se erija sobre consideraciones objetivas y sea proporcionado al fin legítimamente perseguido ${ }^{82}$. En otras palabras, la autoridad del Estado miembro de acogida no debería tener que reconocer como válida una situación jurídica legalmente creada en el Estado miembro de origen, si dicho reconocimiento comporta una amenaza real, lo suficientemente grave para afectar a un interés fundamental de su sociedad.

En estos casos, el orden público, la seguridad y la salud públicas operan como mecanismos que justifican la excepción al ejercicio de un derecho fundamental como es la libre circulación en la Unión Europea y, por tanto, deben interpretarse siempre de manera restrictiva. Sirva como ejemplo, el asunto Sayn-Wittgenstein contra Von Mien (vid. STJUE de 22 de diciembre de 2010), en el que las autoridades austriacas se niegan a reconocer el apellido de una nacional austriaca, tal y como había sido determinado en Alemania, porque dicho apellido incluía un título nobiliario no permitido en Austria con arreglo a su Derecho constitucional. Las autoridades austriacas alegaron que dicho reconocimiento supondría una vulneración de su orden público internacional porque en el ordenamiento jurídico austriaco, la Ley de abolición de la nobleza - de rango constitucional-, establece que los ciudadanos austriacos no pueden utilizar títulos nobiliarios, incluidos los de origen extranjero ${ }^{83}$.

${ }^{82}$ Andreas Bucher, «L'ordre public et le but social des lois en droit international privé», $R C A D I$, n. $^{\circ} 239$ (1993), 9-116.

${ }^{83}$ María Dolores Ortiz Vidal, «Ilonka Fürstin von Sayn-Wittgenstein: una princesa en el Derecho internacional privado», Cuadernos de Derecho Transnacional, n. ${ }^{\circ} 2$ (2011), 304-316. 
En lo que interesa al presente trabajo, cabe plantearse si los Estados miembros deben reconocer los matrimonios entre personas del mismo sexo válidamente celebrados en la Unión Europea o si rechazar este reconocimiento implica un aceptado límite del derecho a la libre circulación y residencia de los ciudadanos de la Unión Europea y de los miembros de su familia.

El punto de partida puede situarse en que el Tratado de Funcionamiento de la Unión Europea señala que el Consejo, a propuesta de la Comisión y previa consulta al Parlamento Europeo, está facultado para adoptar las medidas que estime necesarias para luchar contra cualquier tipo de discriminación, lo que incluye, evidentemente, la discriminación basada en la orientación sexual (art. 19 TFUE). Además, las autoridades y tribunales de cada Estado miembro, cuando aplican Derecho nacional, están obligados a interpretarlo a la luz de la letra y de la finalidad de la norma de Derecho de la Unión Europea, siempre que ello sea posible ${ }^{84}$. Ante esta situación, resulta difícil mantener una posición contraria a la institucionalización de las parejas homosexuales.

A ello hay que añadir que la cláusula de orden público internacional, en el contexto de la libre circulación de personas, sólo puede activarse si supera un test de compatibilidad ${ }^{85}$. Ello significa que el Estado miembro de acogida no puede alegar amparo en el orden público internacional si la medida que pretende aplicar es discriminatoria, no está justificada por razones de interés general y no es proporcional al objetivo que legítimamente persigue ${ }^{86}$.

La pregunta surge espontáneamente, ¿qué papel desempeña la institución jurídica del matrimonio en la sociedad de cada Estado miembro de la Unión Europea? De un lado, es lícito argumentar que la defensa de la institución legal del matrimonio es una cuestión de interés general. Sin embargo, de otro lado, resulta muy difícil justificar que denegar la entrada y la residencia del cónyuge del ciudadano de la Unión sea una medida proporcionada en aras a la defensa de este interés general ${ }^{87}$.

Ante esta situación, las autoridades de los Estados miembros de la Unión Europea no tienen por qué admitir, en su territorio, la válida ce-

${ }^{84}$ STJCE de 10 de abril de 1984, Von Colson y Kamann/Land Nordrhein-Westfalen, as. C-14/83 y STJCE de 10 de abril de 1984, Harz/Deutsche Tradax, as. C-79/83.

${ }^{85}$ Mercedes Soto Moya, «Libre circulación por el territorio de la Unión Europea de los matrimonios del mismo sexo celebrados en España», Revista de Derecho Comunitario Europeo, n. $^{\circ} 43$ (2012), 807-847, esp. 845.

86 Vid. STJUE de 5 de junio de 2018, Coman y Hamilton, as. C-673/16.

${ }^{87}$ Cristina González Beilfuss, Parejas de hecho y matrimonios del mismo sexo en la Unión Europea, (Madrid: Marcial Pons, 2004): 86. 
lebración de matrimonios entre personas del mismo sexo. Sin embargo, ello no es obstáculo para que dichas autoridades reconozcan algunos efectos jurídicos a esa relación. Sirva como ejemplo, la Sentencia del Tribunal Supremo de 24 de enero de 2018, en la que se concede a dos viudas de un soldado marroquí polígamo el derecho a compartir una pensión de viudedad, aunque la celebración de un segundo o ulterior matrimonio en nuestro país - sin que se haya disuelto el primero- está prohibida $^{88}$.

El tratamiento jurídico del matrimonio poligámico en Derecho internacional privado español permite diferenciar dos supuestos: el matrimonio poligámico que pretende celebrarse en España y el matrimonio poligámico que se ha celebrado válidamente en el extranjero y persigue generar efectos jurídicos en nuestro país. En el primer caso, el orden público internacional español impide la aplicación de la Ley marroquí que considere capaz para contraer matrimonio, en España, a un ciudadano que esté ligado por un matrimonio anterior no disuelto (art. 9.1 Código Civil). Ello se debe a que la poligamia es una institución legal que atenta contra los valores y principios más fundamentales de la sociedad española: monogamia, igualdad entre hombre y mujer en el matrimonio y dignidad constitucional de la mujer. En el segundo supuesto, sí que es posible que el matrimonio poligámico, válidamente celebrado en Marruecos, produzca algunos efectos jurídicos en España, siempre que ello tenga por objetivo, en exclusiva, evitar una situación injusta. Negar la pensión de viudedad a la segunda y/o ulteriores esposas que, de acuerdo con su Ley personal, estuvieran simultáneamente casadas con el causante perceptor de una pensión con cargo al Estado español, supondría un trato materialmente discriminatorio para ellas $\mathrm{y}$, a su vez, una desprotección económica, social y jurídica de la familia ${ }^{89}$.

Ello es posible gracias a la figura del orden público internacional atenuado. En lo que interesa al presente trabajo, la celebración de un matrimonio homosexual en aquellos Estados miembros de la Unión Europea cuyos ordenamientos jurídicos lo prohíben, no será posible en ningún caso porque ello dañaría los principios básicos del Derecho de tales sociedades. A diferencia de ello, en el caso de que el matrimonio entre personas del mismo sexo se haya celebrado válidamente en un Estado miembro de la Unión Eu-

88 Sentencia del Tribunal Supremo, Sala de lo Contencioso, Sección 4, Sentencia de 24 enero 2018, Rec. 98/2017 (Texto en CENDOJ: ROJ: STS 121/2018 - ECLI: ES:TS:2018:121).

89 María Dolores Ortiz Vidal, «El matrimonio polígamo y su eficacia jurídica en España: el esperado pronunciamiento del Tribunal Supremo en relación con el derecho a la pensión de viudedad», CEF : Revista del Trabajo y de la Seguridad Social, n. ${ }^{\circ} 424$ (2018), 65-90. 
ropea, se trata de exportar tal situación jurídica con destino a los demás Estados miembros. En este supuesto, al igual que sucedía con la institución jurídica de la poligamia, la intervención de la cláusula de orden público internacional debe limitarse sólo a ciertos efectos derivados de la situación ya creada.

En esta línea de pensamiento, el Tribunal de Justicia de la Unión Europea ha señalado, en el asunto Coman, que la protección de la familia tradicional puede constituir, en determinadas circunstancias, un objetivo legítimo. Sin embargo, denegar la concesión de un permiso de residencia por motivos familiares al miembro de la pareja extranjero y homosexual no es una razón particularmente sólida y convincente que pueda justificar, en las circunstancias del asunto sobre el que se pronuncia, una discriminación por razón de la orientación sexual ${ }^{90}$.

Sólo de esta manera se garantiza que los ciudadanos de la Unión Europea que desean abandonar el territorio del Estado miembro cuya nacionalidad ostentan y quieren establecer su residencia en otro Estado miembro, tengan la certeza de poder continuar su vida familiar. Desde esta perspectiva, la figura del orden público internacional atenuado refuerza la seguridad jurídica y la estabilidad legal de las situaciones creadas en el extranjero, evitando que los particulares implicados sufran un perjuicio elevado.

Ahora bien, las autoridades del Estado miembro de acogida tendrían que aceptar que dos personas que han contraído válido matrimonio homosexual en otro Estado miembro residan allí libremente, en calidad de tales. La autoridad del Estado miembro de acogida reconocería esta situación a los solos efectos de entrada y residencia. No obstante, aislar ese reconocimiento no es una tarea fácil porque existen otros muchos aspectos vinculados a la cualidad de cónyuge que se encuentran estrechamente relacionados con el ejercicio de la libre circulación y residencia ${ }^{91}$. Sirva como ejemplo, el hecho de que deban enfrentarse a importantes dificultades si en el futuro desearan poner fin, en Rumanía, a su matrimonio, modificar o liquidar allí su régimen económico matrimonial o reclamar alimentos si uno de ellos impugnara la validez del matrimonio ${ }^{92}$.

90 Vid. STJUE de 5 de junio de 2018, Coman y Hamilton, as. C-673/16.

91 Santiago Álvarez González, «¿Matrimonio entre personas del mismo sexo para toda la UE?. A propósito de las conclusiones del Abogado General en el asunto Coman», La Ley Unión Europea, n. ${ }^{\circ} 56$ (2018), 5.

92 Pilar Jiménez Blanco, «La movilidad transfronteriza de matrimonios entre personas del mismo sexo: la UE da un paso más», La Ley Unión Europea, n. ${ }^{\circ} 61$ (2018): 5 


\section{Conclusiones}

En la actualidad, la familia constituye una realidad social que presenta un carácter no inmutable. Existen diferentes modelos que varían en función del espacio y del tiempo en el que éstos se ubiquen. Prueba de ello es el hecho objetivo de que no todos los Estados miembros de la Unión Europea admiten la válida celebración de matrimonios entre personas del mismo sexo. Por tanto, existen dos modalidades de matrimonio: los que son válidos en el marco de la Unión Europea y los que lo son a nivel estatal, por la única razón de la diferencia de sexo.

Ante esta situación, el presente trabajo reflexiona sobre si una discriminación basada en la orientación sexual puede obligar a los Estados miembros de la Unión Europea a reconsiderar la institución jurídica del matrimonio, respecto del ejercicio del derecho a la libre circulación y residencia.

El punto de partida se sitúa en que cada Estado miembro posee una identidad social y cultural propia que la Unión Europea respeta (vid. art. 4.2 TUE). Las autoridades de un Estado miembro de la Unión Europea no pueden ser obligadas a admitir el reconocimiento de una situación jurídica que no sintoniza correctamente con su identidad y organización social y cultural.

Sin embargo, en la práctica, la negativa del Estado miembro de acogida a reconocer el matrimonio homosexual válidamente celebrado en otro Estado miembro de la Unión Europea podría incentivar el mantenimiento de dos relaciones formalizadas paralelas que se distinguirían sólo por el sexo del cónyuge. De ello puede desprenderse que esta realidad da lugar a una discriminación fundamentada en la orientación sexual, lo que se encuentra expresamente prohibido en el artículo 21 de la Carta de Derechos Fundamentales de la Unión Europea.

Además, la evolución de la sociedad europea tiende a facilitar la libre circulación de los ciudadanos de la Unión Europea y de los miembros de su familia, respetando su orientación sexual. Valga como ejemplo la actual definición de vida familiar que proporciona la Carta de Derechos Fundamentales de la Unión Europea y que cada vez son más los Estados miembros que permiten la válida celebración en su territorio de matrimonios entre personas del mismo sexo.

En esta línea de pensamiento, el Tribunal de Justicia de la Unión Europea ha señalado, en el asunto Coman, que la protección de la familia tradicional puede constituir, en determinadas circunstancias, un objetivo legítimo. Sin embargo, denegar la concesión de un permiso de residencia por motivos familiares al miembro de la pareja extranjero y homosexual no es una razón particularmente sólida y convincente que pueda justificar, en las 
circunstancias del asunto sobre el que se pronuncia, una discriminación por razón de la orientación sexual.

Ahora bien, este pronunciamiento del Tribunal de Justicia de la Unión Europea no significa que, a partir de este momento, todos los Estados miembros estén obligados a admitir la válida celebración de matrimonios homosexuales en su territorio. No obstante, es necesario que los Estados miembros cuya legislación prohíbe la celebración de matrimonios entre personas del mismo sexo, reconozcan algunos efectos jurídicos a los que se hayan contraído válidamente en otros Estados miembros de la Unión Europea.

En concreto, uno de esos efectos podría ser facilitar la entrada y la residencia en un país cuya legislación prohíbe la celebración de los matrimonios homosexuales, de un nacional de un tercer Estado que se casó con un ciudadano de la Unión Europea, en otro Estado miembro donde sí es legítimo contraer este tipo de matrimonios. Así, el ciudadano de la Unión Europea no se verá privado de la posibilidad de poder regresar al Estado miembro de que es nacional, acompañado de su cónyuge.

De esta manera, se permite el alcance de un justo equilibrio entre los intereses de cada Estado miembro - a la hora de decidir si desean admitir, o no, la celebración de matrimonios entre personas del mismo sexoy los intereses de la Unión Europea - que abogan por facilitar el derecho fundamental del ciudadano de la Unión y de los miembros de su familia a circular y residir libremente en el territorio de los Estados miembros. No obstante, aislar ese reconocimiento no es una tarea sencilla porque existen otros muchos aspectos vinculados a la cualidad de cónyuge que se encuentran estrechamente relacionados con el ejercicio de la libre circulación y residencia, tal y como se puso de relieve en el trabajo.

Ante esta situación, parece aconsejable que las soluciones que se adopten en el marco de la aplicación del Derecho de la Unión Europea y las soluciones de Derecho internacional privado los Estados miembros se alineen, con el objetivo de que el estado civil de una persona no sea distinto en cada Estado miembro. Avanzar en la adopción de medidas aplicables en materia de Derecho de Familia refuerzan la dimensión social del concepto de ciudadanía de la Unión Europea.

\section{Sobre la autora}

María Dolores Ortiz Vidal es Licenciada en Derecho por la Universidad de Murcia. Doctora en Derecho por la Universidad de Zaragoza. Diploma de Estudios Avanzados en Derecho (UNIZAR). Máster de Investigación Avanzada y Especializada en Derecho (UMU). Profesora Contra- 
tado Doctor de Derecho Internacional Público y Relaciones Internacionales en la Universidad de Murcia. Miembro de la Unidad para España de la Unesco «Chair in Bioethics and Medical Law» (Universidad de Haifa, Israel). Miembro de la Cátedra de Economía Social (UMU). Miembro de la Asamblea del Centro de Estudios Europeos (UMU). Miembro del Grupo de Investigación «Derecho Internacional»(UMU). Miembro de la Asociación Española de Profesores de Derecho Internacional y Relaciones Internacionales. Vicedecana de Calidad y Comunicación (UMU) y Coordinadora del Máster propio en Derecho de Familia y Derecho Hereditario (UMU). Sus líneas de investigación engloban: derecho patrimonial internacional y derecho de familia internacional, con especial atención a la protección de menores.

\section{About the author}

María Dolores Ortiz Vidal has a Law Degree from the University of Murcia. PhD in Law from the University of Zaragoza. Advanced Diploma of Advanced Studies in Law (UNIZAR). Advanced Research Master's Degree and Specialized in Law (UMU). Professor Doctor of International Public Law and International Relations at the University of Murcia. Member of the Unit for Spain of Unesco «Chair in Bioethics and Medical Law» (University of Haifa, Israel). Member of the Chair of Social Economy (UMU). Member of the Assembly of the Center for European Studies (UMU). Member of the Research Group «International Law» (UMU). Member of the Spanish Association of Professors of International Law and International Relations. Vice-Dean of Quality and Communication (UMU) and Coordinator of the Master's Degree in Family Law and Hereditary Law (UMU). His lines of research include: international property law and international family law, with special attention to the protection of minors. 


\section{Derechos de autor}

Los derechos de autor (para la distribución, comunicación pública, reproducción e inclusión en bases de datos de indexación y repositorios institucionales) de esta publicación (Cuadernos Europeos de Deusto, CED) pertenecen a la editorial Universidad de Deusto. El acceso al contenido digital de cualquier número de Cuadernos Europeos de Deusto es gratuito inmediatamente después de su publicación. Los trabajos podrán leerse, descargarse, copiar y difundir en cualquier medio sin fines comerciales y según lo previsto por la ley; sin la previa autorización de la Editorial (Universidad de Deusto) o el autor. Así mismo, los trabajos editados en CED pueden ser publicados con posterioridad en otros medios o revistas, siempre que el autor indique con claridad y en la primera nota a pie de página que el trabajo se publicó por primera vez en CED, con indicación del número, año, páginas y DOI (si procede). Cualquier otro uso de su contenido en cualquier medio o formato, ahora conocido o desarrollado en el futuro, requiere el permiso previo por escrito del titular de los derechos de autor.

\section{Copyright}

Copyright (for distribution, public communication, reproduction and inclusion in indexation databases and institutional repositories) of this publication (Cuadernos Europeos de Deusto, CED) belongs to the publisher University of Deusto. Access to the digital content of any Issue of Cuadernos Europeos de Deusto is free upon its publication. The content can be read, downloaded, copied, and distributed freely in any medium only for non-commercial purposes and in accordance with any applicable copyright legislation, without prior permission from the copyright holder (University of Deusto) or the author. Thus, the content of CED can be subsequently published in other media or journals, as long as the author clearly indicates in the first footnote that the work was published in CED for the first time, indicating the Issue number, year, pages, and DOI (if applicable). Any other use of its content in any medium or format, now known or developed in the future, requires prior written permission of the copyright holder. 